Table 2. The four comorbidity indexes discrimination for 1 - and 5 -year survival in patients with RA.

\begin{tabular}{lcccc}
\hline Models & \multicolumn{2}{c}{ 1-year mortality } & \multicolumn{2}{c}{ 5-year mortality } \\
\cline { 2 - 5 } & $\begin{array}{l}\text { Harrell's c- } \\
\text { statistics }\end{array}$ & AIC & $\begin{array}{c}\text { Harrell's c- } \\
\text { statistics }\end{array}$ & AIC \\
\hline Base model & 0.744 & 1868 & 0.777 & 10281 \\
Base model+ CCI & 0.796 & 1783 & 0.802 & 9879 \\
Base model+ ECI & 0.772 & 1829 & 0.793 & 10024 \\
Base model+ MMI & 0.779 & 1821 & 0.792 & 10038 \\
Base model+ & 0.773 & 1817 & 0.791 & 10048 \\
RDCl & & & & \\
\hline
\end{tabular}

Base model included age, gender, income quartiles, urbanization and occupation groups. The Harrell's c-statistic indicates model prediction as the followings: 0.5 (as well as chance), 0.7-0.8 (acceptable), 0.8-0.9 (excellent), and 0.9-1 (outstanding prediction). The AIC statistic was calculated, and a small AIC indicates better prediction of the model.

Disclosure of Interests: None declared

DOI: 10.1136/annrheumdis-2019-eular.4513

\section{AB0260 TREATMENT WITH BIOTECHNOLOGICAL DRUGS ACCORDING TO PRE-DEFINED SELECTION CRITERIA IN PATIENTS WITH RHEUMATOID ARTHRITIS: PRELIMINARY RESULTS OF A SINGLE COHORT}

Daniela lacono, Ilenia Pantano, Serena Fasano, Giuseppe Scalise,

Francesco Ciccia. University of Campania Luigi Vanvitelli, Rheumatology, Naples, Italy

Background: Current recommendations on the treatment of Rheumatoid Arthritis (RA) are based on a treat to target approach, nevertheless which biologic drug should be used in an unresponsive patient is not clarified (1). Such a strategy is essentially justified by the fact that no biotechnological drug has proved to be superior to any other (2).

Recent studies have reported some disease or patient features that are associated with a greater or lesser likelihood of response (3). Nevertheless, an adapted therapy to the single patient and based on physiopathological mechanisms has not been acquired yet.

Objectives: Aim of this study was to evaluate if the choice of a tailored therapy, based on patient and disease features, would be an effective strategy.

Methods: From April $1^{\text {st }} 2017$, at our Department of Rheumatology of the University of Campania, each patient with RA has been characterized, at enrolment, for demographic and disease features, and started a biological Disease-modifying antirheumatic drug based on an established algorithm (Figure 1). Attainment of the targeted end point i.e. remission $(R)$ as assessed by Simplified Disease Activity Index (SDAI) $<3.3$ or at least low disease activity (LDA), SDAl $<11$, has been evaluated at 3,6 and 12 months.

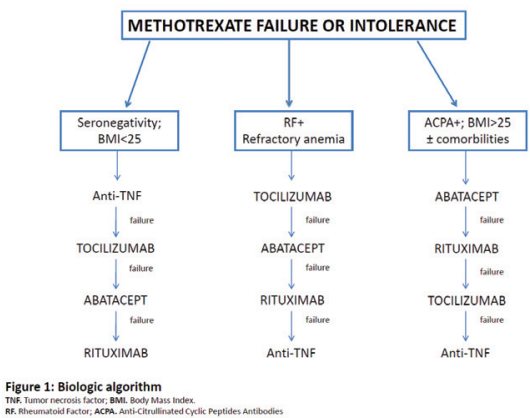

Figure 1

Results: Forty-nine patients were admitted to our centre from April

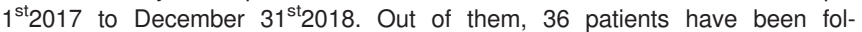
lowed up at least for 3 months and were included in the study (algorithm+ patients). Out of them, $26(72.2 \%)$ reached 6 months of treatment, while $16(44.4 \%) 12$ months of treatment. Among the 26 patients evaluated at 6 months, 23(88.5\%) achieved the targeted end point. At 12 months, $16 / 16$ patients $(100 \%)$ preserved a status of remission or at least low disease activity. We compared our results to those registered, from January 2015 to September 2016, in a RA cohort of 79 patients (RA general cohort). We found a significant difference in regard to attainment of the target at 6 months (23/26 patients, $88.5 \%$ algorithm+ vs 45 / 67 patients, $67.2 \%$ RA general cohort; $p=0.04)$ and at 12 months $(16 / 16$ patients, $100 \%$ algorithm+ vs $40 / 57$ patients, $70.2 \%$ RA general cohort; $\mathrm{p}=0.01$ ) (Table 1). Notably, 32 out of the 79 patients had undergone a biological drug which didn't follow the predefined algorithm. These patients (algorithm- patients) presented a further lower incidence of response with regard to those enrolled according to the algorithm: 22/32 patients $(68.7 \%)$ at 3 months; $p=0.4 ; 17 / 29(58.6 \%)$ at 6 months; $p=0.001 ; 17 / 24$ $(70.8 \%)$ at 12 months; $p=0.03)$

Conclusion: The choice of a personalized approach toward treatment of RA might be an effective strategy to achieve the targeted end point of remission or at least low disease activity in every patient.

\section{REFERENCES}

[1] Smolen JS et al. Ann Rheum Dis 2017;76:960-77

[2] Pierreisnard A et al. Joint Bone Spine. 2013;80:386-92.

[3] Daïen Cl et al. Mediators of Inflammation 2014;2014:386148

Table 1. Comparison of percentage of response between Algorithm + patients (n.36) and RA general cohort (n.79)

\begin{tabular}{lccc}
\hline & $\begin{array}{c}\text { Algorithm+ } \\
\text { patients }\end{array}$ & $\begin{array}{c}\text { RA general } \\
\text { cohort }\end{array}$ & p \\
\hline LDA/R 3 months & $28 / 36(77.7 \%)$ & $51 / 76(67.1 \%)$ & 0.25 \\
LDA/R 6 months & $23 / 26(88.5 \%)$ & $45 / 67(67.2 \%)$ & 0.04 \\
LDA/R 12 & $16 / 16(100 \%)$ & $40 / 57(70.2 \%)$ & 0.01 \\
months & & & \\
\hline
\end{tabular}

Disclosure of Interests: DANIELA IACONO Speakers bureau: PFIZER company, Ilenia Pantano: None declared, SERENA FASANO: None declared, GIUSEPPE SCALISE: None declared, Francesco Ciccia Grant/ research support from: CELGENE, PFIZER, Consultant for: UCB, NOVAR TIS, CELGENE, PFIZER, LILLY, Paid instructor for: UCB, NOVARTIS, CELGENE, PFIZER, LILLY, JANSSEN, Speakers bureau: UCB, NOVARTIS, CELGENE, PFIZER, LILLY, JANSSEN, MSD, ROCHE, AMGEN DOI: 10.1136/annrheumdis-2019-eular.3473

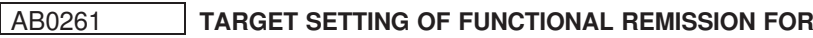 HAND AND WRIST SURGERIES USING GRIP POWER AND PATIENT-REPORTED OUTCOME MEASURES IN PATIENTS WITH RHEUMATOID ARTHRITIS: A PROSPECTIVE COHORT STUDY}

Hajime Ishikawa ${ }^{1}$, Asami Abe ${ }^{1}$, Toshihisa Kojima², Masayo Kojima ${ }^{3}$,

Yoichi Kurosawa ${ }^{1}$, Eriko Hasegawa' ${ }^{1}$, Satoshi Ito ${ }^{1}$, Naoki Ishiguro²,

Akira Murasawa'. ' Niigata Rheumatic Center, Rheumatology, Shibata city, Niigata 957-0054, Japan; ${ }^{2}$ Nagoya University Hospital, Orthopaedic Surgery, Nagoya city, Japan; ${ }^{3}$ Nagoya City University Graduate School of Medical Sciences, Medical Education, Nagoya city, Japan

Background: The treatment aim of rheumatoid arthritis (RA) is achieving and maintaining functional remission via tight medical control. However, if adequate medication is not administered in the very early stage of the disease, surgical reconstruction for the structurally damaged hand and wrist is sometimes required. Objectives: To evaluate the effect of surgical treatment of the hand and wrist $^{(1)}$ and to set the target of functional remission using grip power and patient-reported outcome measures (PROs) at baseline.

Methods: A prospective observational cohort study was performed in RA patients who were scheduled to have primary hand and/or wrist surgeries. Assessments were performed at baseline and 12 months after surgery using grip power (GP), pain visual analogue scale (pain VAS), genera health $(\mathrm{GH})$, disease activity score 28- C-reactive protein(4) (DAS28-CRP (4)), disabilities of the arm, shoulder and hand (DASH), European quality of life scale with five dimensions (EQ-5D), Beck depression inventory -II (BDI-II) and health assessment questionnaire- disability index (HAQ-DI) for all registered patients. Baseline data for each item in the group with $H A Q$ remission (HAQ-DI $\leq 0.5$ ) at 12 months (REM) were compared with those in the group without remission at 12 months (non-REM).

Results: There were 137 sites (63 hands, 74 wrists) in 119 patients whose average age was $62(19-88)$ years and average disease duration was $14(1-45)$ years. Overall, the physical function (GP, pain VAS, DASH, HAQ-DI), quality of life (HAQ-DI, GH, EQ-5D), depression (BDI-II) and disease activity (DAS28-CRP(4)) had significantly improved at 12 months $(p<0.01)$ (Table 1). In the REM group $(n=47)$, the GP and EQ$5 \mathrm{D}$ were significantly higher $(\mathrm{p}<0.01)$ and the HAQ-DI, DASH and BDI-II significantly lower $(p<0.01)$ than in the non-REM group (Table 2). The cut-off value at baseline for achieving HAQ remission at 12 months after surgery was $119 \mathrm{mmHg}$ (sensitivity: 0.70 , specificity: 0.64 ) in GP, 0.81 $(0.81,0.77)$ in HAQ-DI, $36.9(0.74,0.73)$ in DASH, $0.69(0.87,0.74)$ in EQ-5D and $9.5(0.72,0.60)$ in BDI-II. 